\title{
Technological assurance of the quality of processing of products from aluminum alloys with a complex geometric shape using magnetic abrasive processing
}

\author{
Dmitriy Maksimov ${ }^{1, *}$, Radmila Shcheglova ${ }^{1}$, and Dmitriy Klochkov ${ }^{1}$ \\ ${ }^{1}$ Saint-Petersburg Mining University, Mechanical Engineering Department, 2, $21^{\text {st }}$ Line, St. Petersburg 199106, Russia
}

\begin{abstract}
In the presented article, the issue of the implementation of magnetic abrasive processing is considered in order to ensure the quality of surfaces of complex shapes of parts made of corrosion-resistant aluminum alloys. The implementation was carried out through theoretical and experimental research. In a theoretical study, the features of processing corrosion-resistant aluminum alloys, existing and possible schemes for magnetic-abrasive processing of surfaces of complex geometric shapes, including a combination of various working movements of the workpiece and pole pieces, are considered. In an experimental study, the dependence of the quality of the processed surface (roughness) on the size of the working gap between the workpiece and the working pole was determined. The result of the research is the determination of the optimal treatment schemes for surfaces with a complex geometric shape, as well as the derived exponential dependence of the change in surface roughness on the size of the working gap.
\end{abstract}

\section{Introduction}

Nowadays, ensuring the required surface or part quality of a product is a key requirement in machining. Therefore, product finishing becomes the most important part of the part manufacturing process. The final processing of the product significantly affects the technical, productiontechnological and performance indicators of the quality of the product, since there is a direct relationship between the accuracy of processing, surface roughness and the service life of the product [1-2,7-9].

\subsection{Aluminum alloys and products}

Today, in such industries as power engineering, aircraft construction, space engineering, etc., aluminum and its alloys are used for the manufacture of most of the products (up to $90 \%$ of the total mass of products) [3-5].

Aluminum can be obtained in its primary state (pure aluminum) or in the form of alloys with other chemical elements. Alloys can be formed by reacting aluminum with cements such as zinc, manganese, magnesium, iron, etc., which give the primary aluminum new properties.

Aluminum alloys have been used in aircraft construction since 1930, mainly alloys of grades 1100, 2014, 2017, 2024, 3003, 6061, 7075. These alloys are widely used in the aerospace and automotive industries, as they have a high specific strength and can replace steel and cast iron [25,27].
The main areas of application of aluminum alloys:

- Manufacturing of car disks, panels and structures from A356 alloy;

- Pistons, brake discs, drums and piston liners SiCp or $\mathrm{A} 12 \mathrm{O} 3 \mathrm{p}$ or aluminum-silicon alloys with $\mathrm{Si}$ content up to $20 \%$;

- Aircraft structures made of T7451 aluminum alloy;

- Anchor, gears, shafts from T6 aluminum alloy;

- Plating of aircraft from T3 aluminum alloy.

The rest of the applications of aluminum and aluminum alloys are used in civil engineering, in the electrical, electromechanical, electronic and packaging industries, in the production of nanostructures with high mechanical strength and thermal stability (aluminum alloy 6061-T6).

\subsection{SF-6 transformer housing}

\subsubsection{Surface roughness}

The body parts of the gas-insulated transformer are made of the difficult-to-machine AMts aluminum alloy. At the same time, high requirements for roughness $\mathrm{Ra}=0.8 \ldots 1.6$ are imposed on the surfaces of complex-shaped products, which is due to the specifics of the operation of an gas-insulated transformer. Insufficient cleanliness of the surface leads to electrical breakdowns, burning of the working surface of the part, an accident, failure of the gas-insulated transformer [28-30].

\footnotetext{
*Corresponding author: imwacako@gmail.com
} 


\subsubsection{Form requirements}

In addition to the high requirements for the roughness of the working surfaces, high requirements for alignment and roundness are imposed on the parts of the SF6 transformer, which are due to the positioning of the parts in the assembly. This causes the opening of the holes of the parts directly in the assembly, which also complicates the technological process of manufacturing a gas-insulated transformer, since some holes have a complex geometric shape, must have a low surface roughness $\mathrm{Ra}=0.8$ microns [3133]. Obtaining such holes is another problem facing technologists, since the inner surface of the shield of an gas-insulated transformer (Fig. 1, a) cannot be subjected to grinding, since it has large overall dimensions.

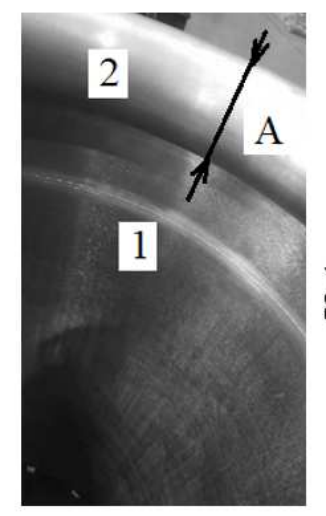

a)

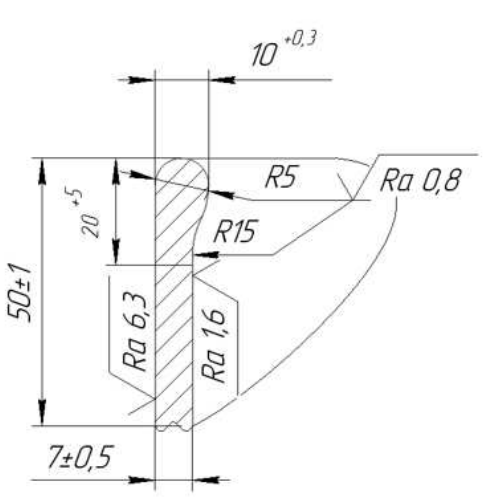

b)
Fig. 1. The inner surface of the screen of a gas-insulated transformer, where 1 (a) - is the inner cylindrical surface of the screen of a gas-insulated transformer; 2 (a) - a complex profile of the end of the screen of an SF6 transformer; $b$ - a sketch of the profile of the screen of a gas-insulated transformer [compiled by the authors]

Manufacturers can finish the working surface of the case using an angle grinder with vulcanite discs.

\section{Theoretical research}

\subsection{Mechanical processing of aluminum alloys}

Let's consider the problem of mechanical processing of aluminum alloys with the peculiarities of their processing. Aluminum and aluminum alloys are some of the most commonly used lightweight metallic materials because they offer a range of distinct mechanical and thermal properties: low specific gravity, high ductility, corrosion resistance, high electrical conductivity. In addition, they are relatively easy to shape, especially by machining. In fact, aluminum and its alloys are considered to be easily machinable materials compared to other light materials such as titanium and magnesium alloys $[6$, $10]$.
However, it is known that alloying aluminum with various elements such as magnesium, manganese, copper, silicon, etc., changes the machinability of the alloy. This change is described by such negative factors associated with the high toughness of aluminum alloys, such as the formation of a buildup on the front surface of the cutting tool, the appearance on the treated surface of a layer with increased microhardness (work hardening), which makes it difficult to achieve a given surface quality, leads to overheating, jamming, breakage of the cutting tool [17-19]. The magnitude of the build-up and work-hardening is influenced by the cutting conditions, the forces arising during the cutting process, the geometry of the cutting tool, and its durability.

Based on the listed features of processing aluminum alloys, various methods of abrasive processing were considered as a final processing method. With the current technological progress, a wide range of enterprises have an urgent need for such a method of finishing the surface of the workpiece, which will provide a low surface roughness $\mathrm{Ra}$ (up to 0.01 microns). There are a number of methods for finishing the surface of the workpiece associated with the use of abrasives: abrasive processing, processing using a magnetic rheological fluid as an abrasive, and magnetic abrasive processing using a magnetic abrasive powder $[9,11,12]$.

\subsection{Magnetic-abrasive processing}

Particular attention should be paid to the process of magnetic abrasive processing, as it is gradually gaining popularity among manufacturers of highprecision products, since it is able to provide a surface roughness $\mathrm{Ra}$ of 0.01 to 0.4 microns, and it can be used for processing both magnetic and nonmagnetic materials. Magnetic abrasive processing is based on the phenomena of a magnetic field and magnetic induction, which is a force characteristic of a magnetic field. The magnetic field can be created by permanent magnets or electromagnets, which are located relative to each other in an order depending on the method of magnetic abrasive processing used [24,29].

The magnetic field is necessary for the formation and retention of the magnetic-abrasive brush at the working poles of the magnetic-abrasive installation, the action of magnetic induction on the magnetic particles of the magnetic-abrasive brush, due to which the tangential $\mathrm{Ft}$ and normal Fn forces are formed, acting on the abrasive particles $[16,18,26]$. When an abrasive particle, held by magnetic particles, comes into contact with the surface of the workpiece due to the action of the normal force Fn and due to the action of the tangential force $\mathrm{Ft}$, removing material. Thus, a high-quality surface layer of the part is formed (Fig. 2). 


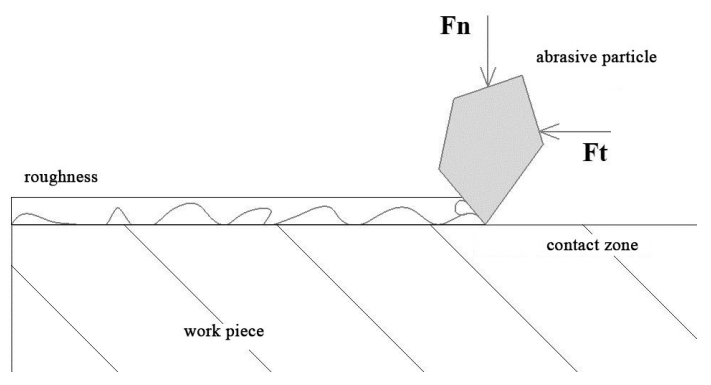

Fig. 2. Scheme of the effect of an abrasive particle on the surface of the workpiece, where: Fn - normal force; Ft tangential force [compiled by the authors]

\subsubsection{Magnetic-abrasive brush}

The mechanism of formation of a magnetic-abrasive brush is a complex system, therefore, when calculating the forces acting on an abrasive particle, researchers of the process of magnetic-abrasive processing usually adhere to certain assumptions $[21,23]$. First, all abrasive and magnetic particles are spherical objects, equally oriented relative to the surface of the workpiece. Secondly, the particle diameter is the same and constant for all particles of the same type, the particles are located relative to each other without voids. Third, the magnetic flux density is distributed evenly throughout the workspace [33-35].

\subsubsection{Magnetic flux}

It should be noted that the magnetic flux density and the uniformity of the magnetic field are one of the key factors affecting the formation of a high-quality surface layer. The distribution of the magnetic field in the processing area determines the shape and rigidity of the magnetic abrasive brush. The characteristics of the magnetic field in the working gap are the density and magnitude of the magnetic flux F, its gradient $[20,22]$. They depend on the shape, size, material of which the working poles are made, the voltage or current supplied to the coils, and the relative position of the working poles relative to each other $[6,8]$.

The magnetic flux acts on the abrasive particle by applying a magnetic force to the magnetic particles that hold the abrasive particle. Due to this effect, the normal force $\mathrm{Fn}$ and the tangential force $\mathrm{Ft}$ are formed, which are responsible for the indentation of the abrasive particle into the workpiece and the removal of material [13-15]. Schematically, the magnetic fluxes that arise in the working gap during the processing of a spherical surface with a flat inductor consisting of successively alternating permanent magnets and pole pieces are shown in Figure 3.

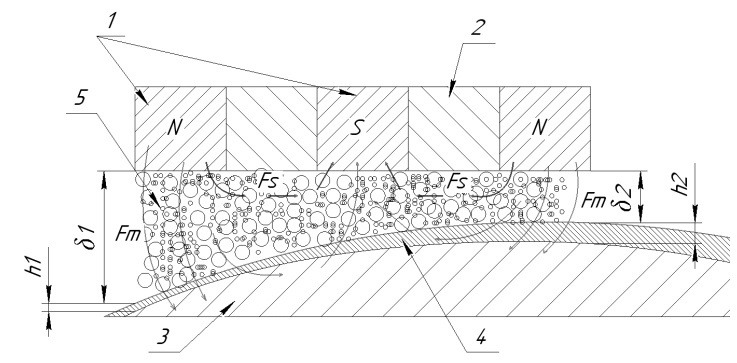

Fig. 3. Scheme of the movement of the abrasive grain and the change in the depth of work hardening when processing a spherical workpiece on an installation with a flat inductor, where: 1 - permanent magnets; 2 - poles; 3 blank; 4 - layer with increased microhardness (peening); $\mathrm{h} 1, \mathrm{~h} 2$ - work hardening depth; $\delta 1, \delta 2$ - working gap; $\alpha$ is the angle of incidence; $\beta$ - angle of reflection [compiled by the authors]

\subsubsection{Distribution of magnetic flux when processing a spherical workpiece}

An analysis of the magnetic flux distribution scheme during processing of a spherical workpiece on an installation with a flat inductor shows that an increase in the working gap $\delta$ negatively affects the quality of the processed surface. Magnetic flux flows pass from one permanent magnet to another, bypassing the workpiece, therefore, the values of the forces Fn and Ft decrease, the removal of material from the surface of the workpiece decreases, the depth of the layer with increased microhardness (work hardening) decreases.

The simulation of the distribution of magnetic fluxes in the working gap between the spherical workpiece and the flat inductor was carried out on a setup with a flat inductor in the ANSYS Maxwell software environment (Fig. 4), which confirmed the above scheme.

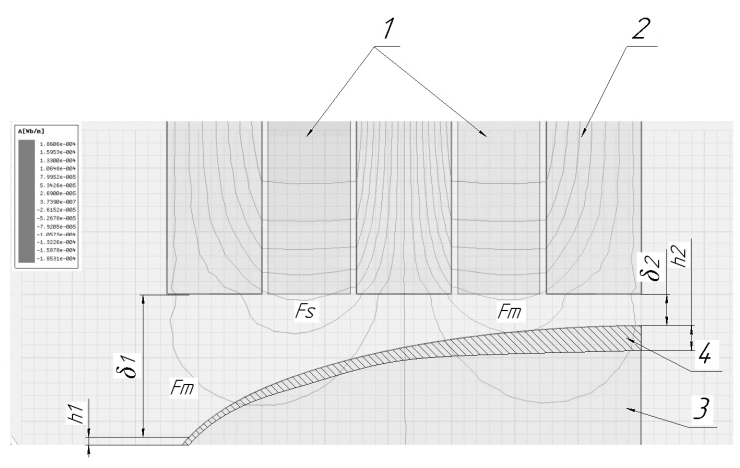

Fig. 4. The distribution of magnetic fluxes and the change in the depth of work hardening when processing a spherical workpiece with a flat inductor, modeled in ANSYS Maxwell, where: 1 - permanent magnets; 2 poles; 3 - blank; 4 - layer with increased microhardness (peening); h1, h2 - work hardening depth; $\delta 1, \delta 2$ working gap; Fm is the main magnetic flux; Fs - magnetic flux flow [compiled by the authors]

Analysis of the modeling shows that the effective use of magnetic abrasive machining in order to 
achieve a given surface quality of a spherical workpiece is possible only if a constant working gap is ensured. The opposite will lead to a forced increase in processing time.

\subsubsection{Schemes of magnetic abrasive processing of spherical blank}

In further theoretical studies, possible schemes for processing a workpiece with a complex geometric shape were proposed (Fig. 5). The fillet of the screen of an gas-insolated transformer, which has several generatrices, is taken as a workpiece.
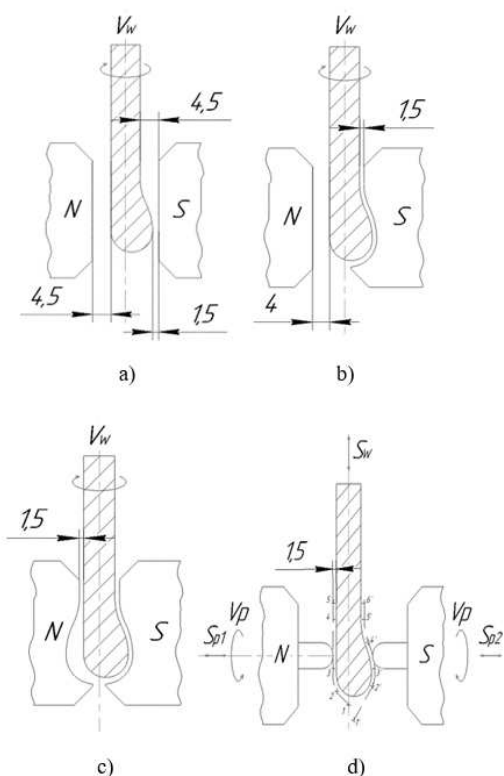

Fig. 5. Schemes of processing the shaped surface of the workpiece between two pole pieces: a) both are flat; $b$ ) flat and shaped; c) both shaped; d) finger shapes [compiled by the authors]

The scheme with two flat-shaped pole pieces does not solve the problem described above, since the use of a flat pole piece when machining a shaped surface does not ensure a constant working gap during machining. The advantage of using flat pole pieces is the possibility of combining two movements - rotation of the workpiece $\mathrm{Vw}$ and rotation of the pole pieces $\mathrm{Vp}$.

The use of a single shaped tip that follows the shape of the workpiece to maintain a consistent working gap during machining will result in uneven surface roughness.

Finger-shaped pole-piece design ensures consistent working gap, desired surface quality. The combination of three movements: the rotation of the pole pieces $\mathrm{Vp}$, the reciprocating movement of the pole pieces $\mathrm{Sp}$, the reciprocating movement of the workpiece $\mathrm{Sw}$ will also have a positive effect on the surface quality - the number of abrasive grains that come into contact with the work surface will increase. But the low productivity of this method of magnetic abrasive processing will complicate the introduction of technology into production, it may turn out to be economically inexpedient $[4-6,8]$.
The most successful option for solving the task to ensure a constant working gap during processing of a shaped part is the option with two shaped tips. The only drawback of this method is the ability to provide only rotational movements of the workpiece and pole pieces.

\section{Experimental research}

\subsection{Magnetic-abrasive device}

After carrying out theoretical studies of the influence of the size of the working gap on the surface quality when processing spherical products made of aluminum alloys, experimental studies were carried out. They were carried out on an installation for magnetic abrasive machining with $\mathrm{CNC}$, the 3D model and design of which are shown in Figure 7. The device for magnetic abrasive machining with CNC includes a base 8 with retaining elements 6 , posts 7 , core bodies 3 , cores 4,5 pole pieces, 1 adjusting screws and 2 solenoid coils.

On the base 8 are installed racks 7 , on which the bodies of the cores 3 are attached. The bodies of the cores 3 serve on one side to provide directionality during the reciprocating movement of the cores 4, which is carried out by means of adjusting screws 1 ; on the other hand, to fix the electromagnetic coils 2 on them, and in order to reduce the load on the core bodies 3 , the electromagnetic coils 2 are installed on the supporting elements 6 (Figure $7 \mathrm{a}, \mathrm{b}$ ).

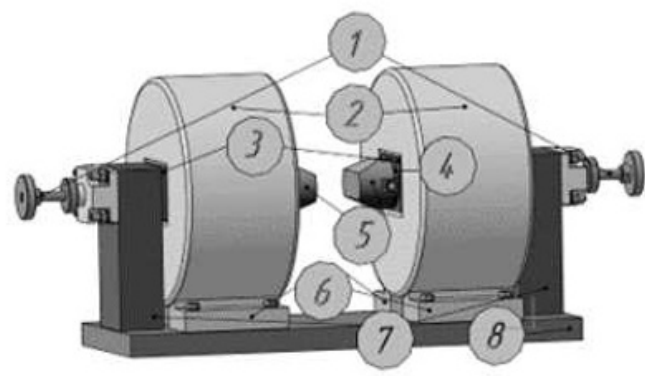

a)

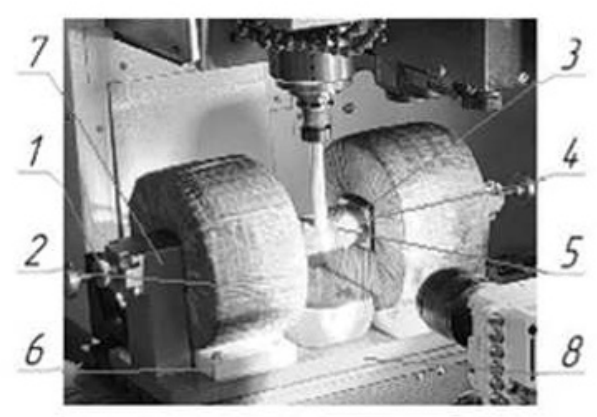

b)

Fig. 6. 3D model (a) and device design (b) for magnetic abrasive machining with $\mathrm{CNC}$ [compiled by the authors] 


\subsection{Magnetic-abrasive parameters}

machining

The processing of spherical billets from the AMts aluminum alloy was carried out with the following parameters of magnetic-abrasive processing (Table 1).

Table 1. Machining parameters

\begin{tabular}{|c|c|c|c|c|c|c|}
\hline $\begin{array}{c}\text { Exper } \\
\text { iment } \\
\text { No. }\end{array}$ & $\begin{array}{c}\text { Proce } \\
\text { ssing } \\
\text { time } \\
t, \\
\text { min }\end{array}$ & $\begin{array}{l}\text { Mag } \\
\text { netic } \\
\text { indu } \\
\text { ction } \\
B, T\end{array}$ & $\begin{array}{l}\text { Fee } \\
\mathrm{d} S, \\
\mathrm{~mm} \\
/ \mathrm{rev}\end{array}$ & $\begin{array}{c}\text { Rota } \\
\text { tion } \\
\text { frequ } \\
\text { ency } \\
n, \mathrm{~s}^{-1}\end{array}$ & $\begin{array}{c}\text { Mag } \\
\text { netic } \\
- \\
\text { abras } \\
\text { ive } \\
\text { pow } \\
\text { der } \\
\text { mass } \\
q, \mathrm{~g}\end{array}$ & $\begin{array}{c}\text { Wor } \\
\text { king } \\
\text { gap } \\
\delta, \\
\text { mm }\end{array}$ \\
\hline 1 & \multirow[b]{2}{*}{12} & \multirow{2}{*}{0,8} & \multirow{2}{*}{50} & \multirow{2}{*}{360} & \multirow{2}{*}{180} & 1,5 \\
\hline 2 & & & & & & 4,5 \\
\hline
\end{tabular}

\subsection{Results of magnetic-abrasive machining}

Figure 8 shows photographs of the surfaces of parts made of AMts aluminum alloy, processed with the above processing parameters with a working gap of $1.5 \mathrm{~mm}$ (Fig. 7, a), $4.5 \mathrm{~mm}$ (Fig. 7, b). The obtained photographs show the difference in the quality of the obtained surfaces. The surface obtained during processing with a minimum working gap of $1.5 \mathrm{~mm}$ is distinguished by the constancy of its structure, the absence of grooves obtained even during turning.

a
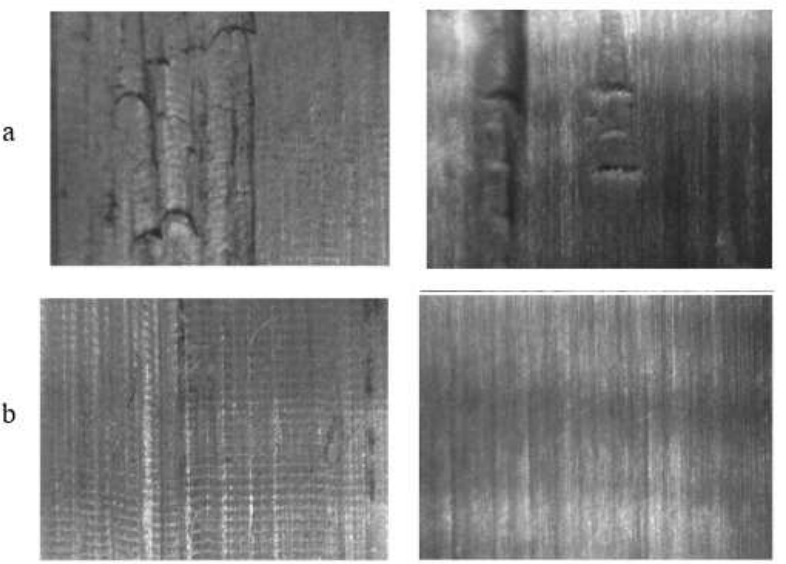

Fig. 7. The surface of parts made of AMts aluminum alloy before and after processing at a working gap: $\mathrm{a}-\delta=1.5$ $\mathrm{mm} ; \mathrm{b}-\delta=4.5 \mathrm{~mm}$ [compiled by the authors]

Also shown are profilograms of the processed surfaces with the above processing parameters with a working gap of $1.5 \mathrm{~mm}$ (Fig. 8, a), $4.5 \mathrm{~mm}$ (Fig. 8, b). The roughness of the raw surfaces of the workpieces was 1.6-1.8 microns. As a result of magnetic abrasive processing, according to the obtained profilograms, it can be seen that for the first workpiece, processed with a minimum working gap of $1.5 \mathrm{~mm}, \Delta \mathrm{Ra}=1-1.2 \mu \mathrm{m}$, for the first workpiece, $\Delta \mathrm{Ra}=0.9-1.1 \mu \mathrm{m}$, the second has $\Delta \mathrm{Ra}=$ 0.6-0.8 microns.

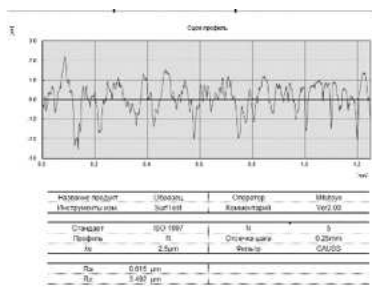

a)

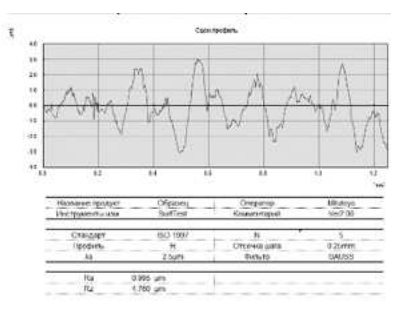

b)
Fig. 8. Profilograms of surfaces of parts made of AMts aluminum alloy after processing at a working gap: a $-\delta=$ $1.5 \mathrm{~mm} ; \mathrm{b}-\delta=4.5 \mathrm{~mm}$ [compiled by the authors]

\section{Conclusion}

Thus, it can be concluded that the quality of the surface layer of spherical parts made of aluminum alloy during magnetic abrasive processing with an increase in the working gap $\delta$ is deteriorating. Based on the results obtained, the following graph and mathematical dependence of $\Delta \mathrm{Ra}$ on $\delta$ can be constructed (Fig. 9), where the exponential dependence is described by the following function:

$\Delta \mathrm{Ra}=\llbracket 1.5962 \rrbracket \wedge(-0.3031 \cdot \delta)$

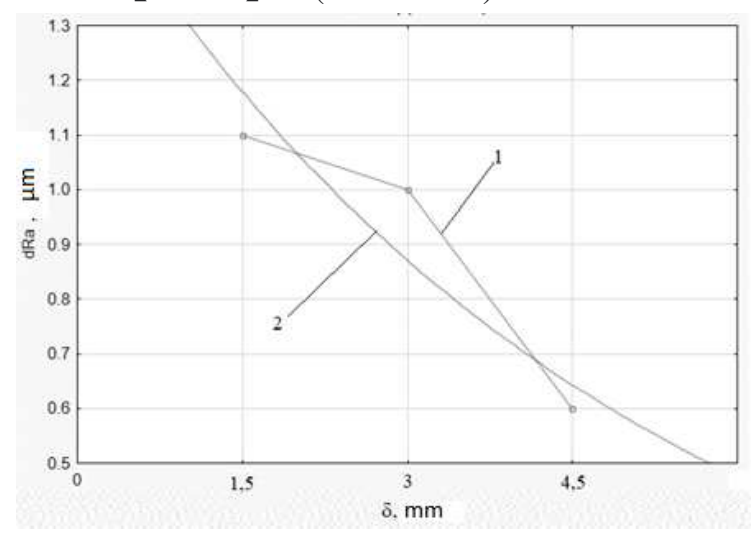

Fig. 9. The dependence of the change in surface roughness $\Delta \mathrm{Ra}$ on the size of the working gap $\delta$, where 1 is a linear dependence; 2 - exponential dependence [compiled by the authors]

In further studies, it is necessary to determine by changing what parameters of the magnetic abrasive machining it is possible to compensate for the increased working gap. At the moment, after the performed theoretical studies, it seems that an increase in the magnetic induction $\mathrm{B}$ and the rotation frequency of the workpiece $\mathrm{n}$ can provide surface quality with an increased working gap, since an increase in the rigidity and performance of a magnetic abrasive brush has a positive effect on the quality of the resulting surface. It should be determined when this increase will be effective and appropriate.

In addition, the most successful option for solving the task to ensure a constant working gap during machining of a shaped part is the option with two shaped tips. The only drawback of this method is the ability to provide only rotational movements of the 
workpiece and pole pieces. The combination of different motions in magnetic abrasive machining significantly increases the machining efficiency, and, therefore, can solve the problem of ensuring an optimal working gap.

\section{References}

[1] L.M. Akulovich, L.E. Sergeev, V.Y. Lebedev, Fundamentals of magnetic-abrasive processing of metal surfaces (Minsk: BSATU, 2012).

[2] L.M. Akulovich, L.E. Sergeev, Technology and equipment for magnetic-abrasive processing of metal surfaces of various profiles (Minsk: BSATU, 2013).

[3] V.E.Babich, Technology of finishing magneticabrasive processing of prefabricated rockcutting tools: dis. cand. tech. sciences, SSI « Physics and Technology Institute » NAS of Belarus, Minsk, 2009.

[4] Y.M. Baron, Magnetic-abrasive and magnetic processing of products and cutting tools. (L.: Mashinostroenie, 1986).

[5] V. Maksarov, A. Efimov, J. Olt, The International Journal of Advanced Manufacturing Technology https://doi.org/10.1007/s00170-021-07975-7

[6] V.I. Zhdanovich, Research of the process of magnetic-abrasive processing of external cylindrical surfaces: dis. cand. tech. sciences, Physics and Technology Institute of the Academy of Science of the BSSR, Minsk, 1974.

[7] V.A. Krasnyy, V.V. Maksarov, D.D.Maksimov, Key Engineering Materials, 854, 133-139 (2020)

[8] F.Y. Sakulevich, Fundamentals of magneticabrasive machining. (Minsk: Nauka i technika, 1981).

[9] A.S. Vasil'ev, A.A. Goncharov Journal of mining institute 235, 60-64, (2019)

[10] G.Y. Liu, Z.N. Guo, S.Z. Jiang, N.S. Qu, Y.B. Li Procedia CIRP 14, 234-238, (2014)

[11] V.V. Maksarov, A.D. Khalimonenko, J. Olt Chernye Metally, 3, 45-51, (2021)

[12] A.D. Khalimonenko , K.P. Pompeev, D.Yu. Timofeev IOP Conference Series: Materials Science and Engineering, 560(1), 012144, (2019)

[13] A.I. Keksin, I.A. Filipenko Topical Issues of Rational Use of Natural Resources. 1, 400405, (2020)

[14] I.V. Gorshkov, M.A. Popov Key Engineering Materials, 854, 64-73, (2020)

[15] D.Y. Ershov, E.G. Zlotnikov, L.E. Koboyankwe IOP Conference Series: Earth and Environmental Science, 87(8), 082016, (2017)

[16] D.Y. Ershov , E.G. Zlotnikov , L.E. Koboyankwe IOP Conference Series: Earth and Environmental Science. 87(8), 082015, (2017).

[17] V.F. Bezyazychnyi, M. Szcerek, M.L. Pervov, M.V. Timofeev, M.A. Prokofiev Journal of Mining Institute, 235, 55-59, (2019)

[18] S. Pirog, Y.E. Shklyarskiy, A.N. Skamyin Journal of Mining Institute 237, 317-321, (2019).

[19] V.A. Kudinov Machine dynimics (M.: Mashinostroenie, 1967).

[20] I.G. Zharkov Vibrations when machining with a razor tool. (L.: Mashinostroenie, 1986).

[21] S.G. Emelyanov Stanki i instrument. 9, 3034, (2011)

[22] E.S. Vorobieva, S.G. Borisenko, E.I. Yatsun Technics and technologies: ways of innovative development. Collection of scientific papers of the 8th International Scientific and Practical Conference. Southwest State University. pp. 185-190. (2019).

[23] E.A. Kudryashov, I.M. Smirnov, E.I. Yatsun, N.A. Khizhnyak Russian Engineering Research. 39(2), 141-146, (2019)

[24] C. J. Rodriguez, Cutting edge preparation of precision cutting tools by applying microabrasive jet machining and brushing. (Kassel: Kassel university press $\mathrm{GmbH}$, 2009).

[25] V.K. Jain, S.C. Jayswal, P.M. Dixit Mater. Manuf. Process., 22, 256-270, (2007).

[26] H. S. Patil, S. N. Soman, American Journal of Materials Engineering and Technology, 2 (3), pp. 29-33, (2014). doi: 10.12691/materials-2-3-1.

[27] J.S Kwak, C.M. Shin Proc. of the Int. MultiConference of engineers and computer scientists. Vol. II, IMECS 20011, March 1618, (2011).

[28] F. Yu. Sakulevich, L. K. Minin, L. A. Olender, Magnetic abrasive processing of precise parts. (Minsk.: "Vysheynaya shkola", 1977).

[29] V.K. Jain, R.K. Jain Int. J. Mach. Tool Manuf. 41 (12), 1689-1704, (2001).

[30] P. I. Yashcheritsyn, Technological bases of processing products in a magnetic field. (Minsk: Physico-Technical Institute, 1997).

[31] S.C. Jayswal, V.K. Jain, P.M. Dixit Int. J. Adv. Manuf. Technol., 26, 477-490, (2005).

[32] Y.M. Baron, S. -L. Ko, J.I. Park Key Engineering Materials 291-292, 291-296, (2005).

[33] S. Yin, T. Shinmura Int. J. of Mach. Tools and Manuf. 44 (12-13), 1297-1303, (2004).

[34] H. Yamaguchi, T Shinmura, M. Takenada, $J$. Jpn. Soc. Prec. Eng, 27, 51-58, (2003)

[35] T. Shinmura, K. Takazava, E. Hitano, T. Aizawa, J. Jpn. Soc. Prec. Eng, 18 (4) 347-348, (1984). 